\title{
LOS INDIOS EN TENOCHTITLAN, LA CIUDAD IMPERIAL MEXICA
}

\section{DimENSIONES DE LA CIUDAD}

La isla original sobre la que se funda Tenochtitlan pudo haber tenido una extensión aproximada de 180 hectáreas hacia 1325, la cual fue creciendo poco a poco mediante la construcción de chinampas (del náhuatl chinámitl-seto o cerco de cañas; cercado hecho de palos y varas entretejidas). ${ }^{1}$

De hecho hubo varios modos de construir suelo artificial tanto para poblamiento como para uso agrícola; uno de ellos lo describe Vargas Machuca en el siglo XVI de la siguiente manera:

"Dentro de esta laguna vive gran cantidad de indios de esta manera, que hacen sus estacadas y las hinchen de tierra, hasta que sube del húmedo del agua huen pedazo encima forman y hacen sus casas". ${ }^{2}$

El hecho de construir suelo artificial fue uno de los resultados más espectaculares logrados por la civilización mesoamericana. Estas parcelas hechas verdaderamente «a mano» van a provocar una transformación del ecosistema local de forma tan radical que permiten un incremento demográfico de gran importancia, ${ }^{3}$ el cual dará lugar posteriormente a la expansión imperialista azteca y al florecimiento general de la cultura mexica. ${ }^{4}$

1 Molina, fray Alonso de: Vocabulario en Lenoua Castellana Mexicana I) Mexicana Castellana. México, 1977.

2 Cita tomada de la obra de Teresa Rojas Rabiela: «La tecnología indígena de construcción de chinampas en la Cuenca de México». En Civilización. México, 1984.

3 Ibidem. pág. 1.

4 Ibidem. 
Hacia 1519 aquello que originalmente había sido un pequeño archipiélago formado por cinco islillas menores (Mixiuca, Tultenco, Zoquiapan, Temascaltitlan e Iliac) y dos grandes (Tenochtitlan $y^{\prime}$ Tlatelolco) se había convertido a través de doscientos años en un solo conjunto urbano fraccionado por canales 'y acequias y rodeado totalmente de agua; estaba, a su vez, unido a tierra firme por medio de tres calzadas hechas de pilotes de madera, piedra y tierra aplanada. Hacia el norte salía la calzada de Tepeyac, al poniente Tlacopan y al sur Iztapalapa.

Tanto Tenochtitlan como Tlatelolco duplican su superficie original ${ }^{5}$ mediante la construcción de chinampas usadas como tierra urbana, es decir, para habitar allí y no para sembrar como sería el caso de las chinampas de la ribera del lago, recalcando con ello la calidad urbana de la población tenochca; según Gibson, en el momento de la conquista muchos indios de la ciudad ni siquiera tenían el más elemental conocimiento agrícola ${ }^{6} \mathrm{y}$ además las parcelas eran tan pequeñas que no alcanzaban para sostener a una famitia; ${ }^{7}$ por otro lado, la enorme cantidad de alimentos que importaba la ciudad confirma lo anterior. ${ }^{8}$

Aunque todos los cálculos, tanto de población como de dimensiones, son hipotéticos, se ha encontrado evidencia arqueológica en las excavaciones que se han hecho durante la construcción de las obras del Metro que indica la posibilidad de que la ciudad hubiera alcanzado un área mayor que la que se había estimado anteriormente. ${ }^{9}$

En el momento del contacto pudo haber tenido la isla un

5500 Planos de la ciudad de México, 1325-1933, editado por Ethel Herrera y Concepción de Ita Martínez. México, 198z; plano de la página 22.

6 Gibson. Charles: Los aztecas bajo el dominio español (1590-1810). México. 1980, pág. 406.

7 Calnek, Edward A.: «Conjunto urbano y modelo residencial en Tenochtitlan», en Ensayos sobre el desarrollo urbano de México. México, 1974.

8 Consultar sobre el tema las cantidades que aparecen en El Códice Mendocino o bien el estudio de Molina Fábregas: El Códice Mendocino y la Economía de Tenochtitlan, editado por la Biblioteca Mexicana en México.

9 Calnek, Edward A.: \&The Internal Structure of cities in America, precolumbian cities. The case of Tenochtitlan». En Urbanización y Proceso Social en América. págs. 347-350, Lima, 1972, pág. 348. 
área de 750 hectáreas, es decir aproximadamente cuatro veces mayor cue la isla original. ${ }^{10}$

\section{DI:NSIDAD DF, POBLACIÓN}

Ciertos investigadores contemporáneos calculan que para 1519 , la ciudad, con su gemela Tlatelolco, tendrían una población aproximada de 300.000 habitantes; "otros hablan de 150.000 a 200.000 habitantes, ${ }^{12}$ lo cual daría una densidad de ocupación de alrededor de 12.500 a 13.000 habitantes por kilómetro cuadrado asentados en terreno predominantemente chinampero; ${ }^{13}$ Gibson menciona una población de 250.000 a 400.000 habitantes en ese momento. ${ }^{14}$ Por otra parte, según los cálculos de los españoles de aquella época, había 60.000 y, si tomamos en cuenta la cifra de Calnek de 5 a 7 habitantes por casa, ello arrojaría un total de 300.000 a 350.0000 habitantes para 1521 en Tenochtitlan y Tlatelolco, lo cual coincide con los cálculos tanto de Gurría Lacroix como de Gibson.

Si bien las cuentas hechas en el siglo XVI son en general poco fiables por diversas razones de índole metodológica, ${ }^{15}$ todas ellas,

10 Garcia Ramos, Domingo: Iniciación al urbanismo. México, 1965, pág. 265.

11 Cálculos hechos por el historiador J. Gurría Lacroix, quien no especifica concretamente sus fuentes en relación a la demografía; en términos generales la bibliografía usada por dicho autor se basa en los cronistas espãñoles del siglo XVI, Vid. «La Conquista de México» en Historia de México. México, 1978, tomo V, pág. 970.

12 Edward A. Calnek, por su parte, se basa para los cálculos de población en estudios de genealogias y en datos de censos hechos en el periodo colonial tem-

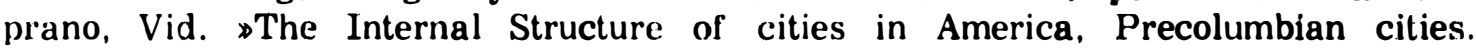
Tenochtillan».

13 Sanders, William: $₫ \mathrm{~A}$ tale of three cities, energetics and urbanization in prehispanic Central México» en Prehistoric Settlements Pattern. pág. 273, Ungt: v. Seventhal, Albuquerque, 1983, págs. 24:3-291.

14 Gibson presenta sus estimaciones sobre población basándose en las encuestas hechas hacia 1561 y 1562 con objeto de delimitar a la población tributaria; las cifrăs se encuentran publicadas en Scholes, F. V. y Adams, E. B.: Sobre el Modo de Tributar los Indios de Nueva España a su Magestad 1561-1564 (México" 1958), así como en la obra de Miranda. José: El Tributo Indigena en la Nueva España durante el siglo XVI. México. 1952. Gibson toma en cuenta también el estudio de Cook y Simpson: The Population of Central Mexico in the sixteenth century. Berkeley, 1948.

15 Cook Sherburne F. y Woodrow Borah: On the credibility of contemporary testimony on the population on Mexico in the sixteenth century en eSumma Anthropologica». México, 1966, págs. 229-240; Ensayos sobre historia de la población. México y el Caribe. México, 1977. 
sin embargo, coinciden en hablar de grandes cantidades de gente que habitaba la ciudad, así como en señalar siempre poblaciones mayores de 100.000 habitantes. Torquemada dice que la ciudad tendría unas 120.000 casas y más de 300.000 vecinos; ${ }^{16}$ Ixtlilxúchitl afirma que en 1520 las casas llegaban a 140.000. ${ }^{17}$

Tenochtitlan concentraba a toda la nobleza mexica, los pipiltin descendientes de Acamapichtli, que eran los que ocupaban los puestos claves de la organización estatal. ${ }^{18}$ Los pocbtecas, o comerciantes que en el momento del contacto se perfilaban como una clase de rango económico elevado sin llegar a formar parte de la nobleza, ${ }^{19}$ y los macebualtin, que eran el grueso de la población, dedicados a labores artesanales, comerciales, agrícolas o de pesca y caza, las cuales se combinaban generalmente con servicios de tipo civil, militar o religioso. ${ }^{20}$

Había también grupos inmigrantes viviendo de manera permanente en la ciudad, ${ }^{21}$ algunos de los cuales eran artesanos de importancia como los lapidarios de Xochimilco que menciona Torquemada, ${ }^{22}$ o los refugiados de Huejotzingo que se establecieron también en Tenochtitlan, ${ }^{2.3}$ sin olvidar a los tlamama que eran de diferente origen étnico. ${ }^{24} \mathrm{Y}$ por último, la presencia siempre histórica de gente que por extremada pobreza o por mil razones más se establecía en la ciudad. ${ }^{25}$

16 Torquemada, fray Juan de: Monarquia Indiana. México, 1977, vol. IV, lib. XI, cap. IV, pág. 17.

17 Alva Ixtlilxóchitl, Fernando de: Obras Históricas. México, 1891-1892, II, pág. 55 .

18 Castillo F., Víctor M.: Estructura económica de la sociedad mexica, según las fuentes documentales. México, 197£, pág. 133.

19 Ibidem, pág. 134.

20 Ibidem, pág. 133.

21 Durán, fray Diego: Historia de las Indias de Nueva España e Islas y Tierra Firme. México, 1867, págs. 213-214.

22 Torquemada, Monarquía Indiana, vol. I, cap. II.

23 Calnek, The Internal Structure..., pág. 348.

24 Castillo, La estructura..., págs. 110-113; tlameme, del verbo meme nitla, cargar a cuestas: Tlamama $=$ cargado (Fray Alonso de Molina, Vocabulario en Lengua...). Los tameme, Tlameme o Tlamama eran los cargadores del México antiguo, constituían el último sector del sistema social, semejante al que ocupan hoy los llamados «macheteros» o cargadores de la ciudad de México.

25 Alvarado Tezozomoc, Hernando: Crónica Mexicana. México, 1944; Calnek, The Internal Structure..., pág. 348; Castillo, La estructura..., pág. 112. 
En añadidura a lo anterior, debió haber también una población flotante de considerable importancia, ya que al ser Tenochtitlan la cabeza del imperio mexica era ésta el recipiente de toda la red tributaria de los pueblos sometidos, de lo cual se deduce la existencia de un movimiento importante de bienes y la entrada a la ciudad de los más diversos tributos en cantidades considerables. ${ }^{26}$

Motolinía distingue entre «los moradores» y la «gente», como queriendo señalar dos tipos de habitantes, es decir, morador sería tal vez «el que habita o está de asiento en un paraje» ${ }^{27}$ dando la idea de permanencia. Gente, quizás, que está de paso, es decir, la población flotante que llegaría a la ciudad a tratar algún negocio.

Las comunicaciones del área se enfocaban en su mayoría hacia la capital mexica; el ochpantli, por ejemplo, era un sistema de caminos que ligaba varias ciudades importantes todas ellas en dirección a Tenochtitlan. ${ }^{28}$ Esta red caminera funcionaba de la manera siguiente:

Desde

Por medio del

Hacia

Tlaxcala

Cholula

Huejotzingo

Texmelucan

Ochpantli

TENOCHTITLAN ${ }^{29}$

Chalco Atenco

Tlalmanalco

Es decir, que el núcleo de todo el sistema era, evidentemente, Tenochtitlan; hay que recordar que en tiempos prehispánicos el acarreo de todo tipo de bienes lo hacían los tamemes (tlamama),

26 Motolinía (Fray Toribio de Benavente): Memoriales o libro de las cosas de la Nueva España y de los naturales de ella. México, 1971, pág. 205.

¿7 Diccionario de la Real Academia de la Lengua.

28 Hassig. Ross: Trade, Tribute and Transportation. The sixteenth century political economy of the Valley of Mexico. Oklahoma, 1985, págs. 31-32.

29 Ibidem. 
ya que no había bestias de carga; ${ }^{30}$ aquéllos cargaban sobre la espalda en unos contenedores llamados petlacalli ${ }^{31}$ y eran por lo general personas muy pobres, especialmente en las ciudades, en donde había cantidades importantes de individuos sin tierras. ${ }^{32}$

El tráfico de canoas se estima entre las 100.000 a 200.000 unidades en el Valle durante los principios del siglo XVI, algunas de ellas con capacidad hasta de 60 pasajeros: ${ }^{33}$

"Hahía en México muy muchas acales o harcas para servicio de las casas e otras muchas de tratantes que venían con hastimentos a la ciudad y todos los pueblos están llenos de harcas que nunca cesan de entrar y salir de la cibdad. que eran innumerablesw. ${ }^{34}$

Se puede suponer que el movimiento de la ciudad fue sumamente importante; no hay que olvidar que la localización de México propiciaba una abundancia de población al estar asentada en una rica zona de altísima productividad agrícola. Simplemente la zona chinampera de Xochimilco-Chalco pudo haber producido alimentos suficientes para 100.000 personas; ${ }^{35}$ hay probabilidades de que Tenochtitlan-Tlatelolco fuera la ciudad más grande del mundo occidental en $1519 .{ }^{36}$

Según Motolinía, en la Europa de la época había «pocas cibdades que tengan tal asiento y tal comarca, tantos pueblos alrededor de sí y tan bien situados... y tan opulenta cosa como Tenochtitlan e tan llena de gente». ${ }^{37}$ Miles visitaban la ciudad por asuntos rela-

30 México prehispánico carecía de vehículos de rueda y de animales de tiro: si bien se han encontrado pequeños juguetes con ruedas en la región del Golfo, la rueda no se usó para vehículos posiblemente por la falta de bestias de tiro. (Hassig. Trade... págs. 31-32). cacaxtli.

31 De petlatl = tapete y calli = casa ; usaban también unas cajas llamadas

32 Castillo, La Estructura..., págs. 111-112.

33 Hassig, Trade..., pág. 62.

34 Motolinia, Memoriales, pág. 211.

35 Armillas, «Gardens on Swamps», en Rojas, Beatriz: La Agricultura Chi. nampera. Méxic, 1983, págs. 175.

36 Gibson, Los aztecas bajo el dominio espantol, pág. 386.

37 Motolinía, Memoriales, pág. 205. 
tivos al mercado; ${ }^{38}$ otros llegarían a prestar trabajo como parte del tributo ofrecido a Tenochtitlan; con respecto a la población flotante el mismo Motolinía comenta «que eran inumerables», que los indios que llegaban «eran sin cuento ca hervían por el agua y por las calles». ${ }^{39}$ Se sabe también de la venta de comidas preparadas para los viajeros; había dignatarios, nobles o caciques de otras provincias visitando la corte mexica, algunos de los cuales mantenían casas de manera permanente en la ciudad; nos habla Sahagún de un edificio que se llamaba yopicalco y también cocolco, en donde se aposentaban los señores y principales que venían de lejos a visitar el templo, especialmente los de la provincia de Anahuac; ${ }^{40}$ todo ello nos habla de una ciudad perfectamente preparada para recibir visitantes, que de una u otra manera constantemente fluían a ella.

De manera que entre la población mexica propiamente dicha, los cargadores diversos, la fuerza de trabajo para tributar venida del exterior, los inmigrantes asentados permanentemente en la isla y los visitantes varios, la ciudad debía estar densamente poblada, pero también de manera un tanto heterogénea en cuanto a composición. Suponemos que la ciudad hacía las veces de centro cosmopolita del altiplano mexicano, siendo el punto receptor de una multiplicidad de movimientos.

\section{URBANIZACIÓN}

Es sumamente difícil precisar cómo sería el patrón de las casas indígenas en el área que luego ocupó la traza española, el centro de Tenochtitlan. Tal vez hubo un solo patrón en toda la ciudad; o tal vez, en tiempos prehispánicos, hubo diferencia entre un centro

38 Díaz del Castillo, Bernal: Historia Verdadera de la conquista de la Nueva España. México, 1950, pág. 176.

39 Motolinía, Memoriales, pág. 208. pág. 163.

40 Sahagún. Historia General de las cosas de Nueva España. México, 1979 
ordenado y zonas suburbanas improvisadas; o el desorden mencionado por los españoles había sido provocado por el desplazamiento tras la conquista.

A pesar de este aparente desorden quizás se puede hablar de tan sólo uno de los patrones de asentamiento aborigen que responde a necesidades muy concretas de su tiempo y de su espacio. El urbanismo usado en Tenochtitlan, así como en el resto del área chinampera, tiene antecedentes muy antiguos en Mesoamérica y en el Valle de México, prueba de lo cual es la existencia de Teotihuacan o bien, fuera de la Cuenca, las ciudades de Xochicalco en el actual estado de Morelos, Tula en Hidalgo o Chichen-Itzá en Yucatán, todas de trazos axiales y orientaciones precisas. ${ }^{41}$ Dicho urbanismo ideado originalmente por los sacerdotes-gobernantes con el objeto de colocar el templo en un lugar preponderante, provoca un centralismo ${ }^{42}$ que se materializa en la forma de la plaza central, elemento que también tiene una gran antigüedad en el Valle de México. ${ }^{4.3}$ Según la Crónica del padre Acosta, ${ }^{44}$ la urbanización de la ciudad se inicia cuando los mexicas construyen una pequeña capilla o ermita para su dios, la cual va a señalar el centro de la ciudad. Todo ello siguiendo las órdenes de Huitzilopochtli, interpretadas por los sacerdotes, casta gobernante del grupo mexicano. ${ }^{45}$

Del punto central arrancan todas las calles con cierto orden que se va diluyendo conforme se alejan hacia afuera; se insinúa

41 Fernández, Justino et al: Planos de la Ciudad de México, S. XVI y XVII. Estudio historico, urbanistico y bibliográfico. «XVI Congreso Internacional de Plani. ficación y de la habitación». México, 1938, pág. 71.

42 Lombardo de Ruiz, Sonia: Desarrollo Urbano de México-Tenochtitlan según las fuentes históricas. México, 1973, pág. 50.

43 Sanders, William: eSettlement Patterns» en: Handbook of Middle American Indians, Social Anthropology. Austin, 1967, vol. VI, pág. 83; Vaillant, George C.: Aztecs of México, London, 1965, pág. 114. pág. 329.

44 Acosta, Joseph de: Historia Natural y Moral de las Indias. México, 1979,

45 Según fray Diego Durán. Huitzilopochtli ordenó a cada uno de los señores del grupo mexica que se instalara con sus parientes en cada uno de los cuatro barrios principales de Tenochtitlan, «tomando en medio la casa que para mi descanso habéis edificado»: casi todas las crónicas coinciden en señalar el centralismo urbano desde su fundación. 
en todo ello una forma radial que pudo haber sido característica de las ciudades fundadas sobre islas o penínsulas como Xochimilco, Cuitlahuac, Mizquic, en el área chinampera, y que se pudo haber dado en la isla tenochca. ${ }^{46}$

Como es bien sabido, Tenochtitlan estaba dividida por dos ejes centrales que daban como resultado cuatro secciones o cuadrantes; éstos son las zonas que, según la tradición, originaron la ciudad mexica; surge así, una simple subdivisión que implica ya un orden espacial del cual se va a derivar toda la ciudad. Hay quien señala que dicha subdivisión obedece al hecho de que Tenochtitlan fue fundada por cuatro grupos étnicos diferentes, los mexica, tlacohcalca, huitznahuaca y cihuatecpaneca, ${ }^{47}$ que se asientan en las distintas "secciones de la ciudad. El eje de la calzada a Iztapalapa (actual calle de Pino Suárez), combinado de manera cruciforme con la calzada a Tacuba, pudo haber tenido su origen en la división primera que supuestamente se hace cuando la fundación, es decir, entre los cuatro grupos étnicos; posteriormente, los ejes de Tenochtitlan, adquieren importancia por la comunicación con tierra firme, ya que conforme va creciendo el intercambio, las vías de comunicación para realizarlo toman un carácter esencial, siendo entonces básicas las calzadas.

Se podría pensar que a partir del reinado de Itzcoatl, cuando se actúa con mayor organización, el plano toma un carácter más formal, construyéndose la primera calzada, hacia Iztapalapa, que va a abrir el acceso directo a tierra firme. Por otro lado, el carácter chinampero de Tenochtitlan obligaba casi a llevar un orden en la

$46 \mathrm{El}$ área chinampera del sur del Valle de México que formaban las antiguas provincias de Chalco y Xochimilco y que hoy en día equivale a las poblaciones de Chalco, Xochimilco. Tlalpan, Tláhuac y Milpa Alta observaba, según Sanders, un patrón de asentamiento agrupando lotes de casas de manera un tanto irregular: lús fotos aéreas de la región muestran dicho fenómeno con un barniz superficial del patrón en damero español: sin embargo en Mixquic la parrilla o damero no aparece. sino que en el centro hay una plaza adonde convergen calles y canales radialmente que posteriormente se pierden en las afueras de la población. Sanders, «Settlement Patterns», págs. 53-86.

47 Reyes Garcia, Luis, inédito: Vaillant, a su vez, afirma que el plano de los pueblos aztecas tendía a ser rectangular puesto que la tierra se hallaba dividida entre los distintos clanes, lo cual obligaba a seguir dicho orden. (Vaillant, Aztecs.... pág. 144). 
distribución urbana puesto que las chinampas tienden a adoptar una forma regular. ${ }^{48}$

Se cree que entre los siglos XIV y XVI, la construcción de chinampas sobre los pantanos de la cuenca Xochimilco-Chalco obedecía a una empresa programada y bien planeada, ${ }^{49}$ de manera que si esto era así en el área rural se puede suponer que la capital tenochca, como punto central de toda la región y asiento del estado, seguía alguna forma de planeación urbana bien organizada.

La división territorial en la ciudad guardaba, además, especial importancia, ya que estaba íntimamente ligada con la actividad económica. Suponemos que en Tenochtitlan la división del trabajo se realizaba por barrios así como en Texcoco ${ }^{50} \mathrm{y}$ cierta actividad religiosa también, ya que cada barrio tenía una deidad que fungía como patrona del barrio y de la ocupación principal de ese barrio. Este tipo de asentamiento es, por otro lado, muy antiguo en Mesoamérica puesto que aproximadamente 1.000 años antes de Tenochtitlan, en el período Clásico, se encuentra organizada de la misma manera. Las evidencias de superficie y de excavación arqueológica indican que esa ciudad estaba dividida en barrios ocupados por diversos artesanos como eran los talladores de obsidiana, los alfareros, los comerciantes y también barrios de carácter étnico como sería el caso del barrio de oaxaqueños. ${ }^{51}$

48 Tras el estudio del Códice llamado «Plano en papel maguey» Circa, 1558, los investigadores Manuel Toussaint y Justino Fernández han demostrado que casi toda la isla estaba trazada posiblemente de manera un tanto ordenada y con un plan regulador que funcionaba cuando menos en el centro de la misma. El mencionado Códice registra un fragmento de la ciudad posiblemente situada en la parte este, es decir, fuera del núcleo central; la traza alli sigue siendo bastante regular (Fernández, Toussaint, et al.). Por su parte Calnek, al estudiar dicho códice, rechaza la proposición de Justino Fernández y aflrma que dicho plano no es necesariamente de Tenochtitlan; si así lo fuera, el área señalada dentro de él no es la que suponen Fernández y Toussaint; de cualquier manera, aunque existe divergencia de opiniones en cuanto al punto que ilustra el plano, éste indica con claridad la presencia de un orden en el área estudiada (Calnek. The localization of the sixteenth centurll map called the «Maguey Plan», en «American Antiquity», vol. 38, núm. ¿, 1973).

49 Armillas, Gardens..., pág. 1774.

50 Motolinía, Memoriales, pág. 236.

51 Millon, René: The Teotihuacan map. Urbanization at Teotihuacan, Mexico. Austin and London, 1921. 
Parece que en T'enochtitlan hubo una correlación entre actividades, barrios y deidades, presentando todo ello una división social del trabajo muy relacionada con la división territorial de la ciudad. ${ }^{52}$

BARRIO

OCUPACIÓN

DEIDAD

Yopico

Plateras, aurífice, xomichanques tratantes de agua, señores y reyes, Calmecac.

Totec, Xipe, Coatlatona, Chalchitlicue, Tlaloc,

Tequiztli-mayahuel.

Huitznahuac Señores, pescadores, Calmecac. Huitzilopochtli, Opochtli, Huitznahuac, Centzonhuitznahuac, Tezcatlipoca.

Itepeyoc Señores

Huitzilopochtli.

Amantla

Tultecayotl, labradoras, tin-

Tizahua, Macuitoreras, plumeras, pintores. locelotl Machuiltochtli, Xihuitlati.

Pochtlan

Mercaderes

Los mercados en Amantla con Yiacatecuhtli.

Atlauhco Mercaderes

Auachtlan Mercaderes

Acxotlan Mercaderes

Nahui Ehecatl, Chiconquiahuitl,

52 Monzón, Arturo: El Calpulli en la organización social de los Tenochca. México, 1983, pág. 73. 
BARRIO OCUPACIÓN

DEIDAD

\author{
Xomocuil, \\ Cochimetl, \\ Yacapitzahuac, \\ Nacxitl, \\ Chalmecacihuatl, \\ Tlamatzincatl, \\ Izquitecat], \\ Coatlicue.
}

Atempan Curanderos y adivinos

Toci madre de lo dioses.

Tzonmolco

Hacían atavío principal del señor, Calmecac.

Xiuhtecuhtli, Huehueteotl, izcozozauhqui.

Tzapotlan

Veindedores de Uxitl
Petateros
Lapidarios

Tzopotlatena, Nappatecuhtli, Chicnahuiitzcuintli, Nahuapilli, Cinteotli, Cihuacoatl. ${ }^{53}$

El cuadro anterior nos muestra la organización que guardaba la división territorial citadina, reforzando nuevamente la idea del alto valor que debe haber tenido la tierra tenochca.

Por otro lado, el asentamiento urbano dentro de la ciudad refleja, asimismo, un orden estratificador en el cual el centro actúa

53 Tabla de correlación de barrios-calpullis, templos-calpullis, ocupaciones y deidades en Tenochtitlan hecho por Arturo Monzón, quien, a su vez, se basa en Sahagún, Historia General... y en Torquemada, Monarquía Indiana (Monzón, Ibidem. pág. 75). 
como polo de atracción, lugar receptor de la mayor inversión económica y por lo tanto de mayor valor.

Los artesanos y comerciantes de importancia se encontrarían dentro de la ciudad rodeando quizás el área que podríamos llamar super elitista o gubernamental. ${ }^{54} \mathrm{Hacia}$ afuera predominan las casas con chinampas, que nos hablan de una mayor ruralización, es decir, con una mayor superficie de cultivo que de habitación.

Por lo anterior, y a partir de las investigaciones hechas en los setentas por Calnek, se puede suponer que la ciudad estaba dividida en tres zonas principales distribuidas de manera más o menos concéntrica, siendo el núcleo de todo ello el centro ceremonial, en donde se concentraban los poderes públicos religiosos y los palacios de la alta nobleza. Después vendría una zona «residencial» formada por casas con pequeñas chinampas de forma rectangular y con un plano ordenado, de alta densidad poblacional y que sería precisamente la masa de la ciudad, la de la vida diaria: ${ }^{55}$ la de lo cotidiano. Por último, habría también una tercera zona que podría considerarse como suburbana, en donde la densidad poblacional va decreciendo a medida que se va alejando del centro, así como las dimensiones de las áreas en donde lo rural va sobreponiéndose sobre lo urbano, con un planeamiento menos regular y menos ventajas, siendo el modo de vida posiblemente más pobre. ${ }^{56}$

54 En el rescate arqueológico hecho durante el año de 1986 en el sitio actualmente llamado Plaza Banamex, situado entre Isabel La Católica y Venustiano Carranza, muy cerca de lo que fue el Recinto Ceremonial, se encontró material prehispánico que indica la presencia de un muy importante taller de obsidiana. Dicho hallazgo hace pensar en la existencia de un área artesanal importante.

55 Tanto para Teotihuacan en el clásico como para Tula posteriormente, se ha aplicado el modelo de un centro que ubica los poderes rodeando una zona residencial de categoría que, a su vez, se encuentra rodeada de viviendas comunes. Noel Morelos ( $\propto E$ El concepto de unidad habitacional en el altiplano». En Manzanilla, Linda: Unidades habitacionales mesoamericanas y sus áreas de actividad. México, 1986, págs. 193-220) sigue la idea de la Escuela Ecologista de Chicago, que propone el modelo de Burges (1925) en donde los espacios urbanos se distribuyen en forma de anillos concéntricos a partir del centro de la ciudad; aplicando dicho modelo a Teotihuacan (Morelos, pág. 198). Blanca Paredes aplica el mismo patrón para toda la Cuenca de México en el período postclásico ( «La unidad habitacional en la Cuenca de México, período postclásico». En Manzanilla, Unidades habitacionales...).

56 Price, Bárbara: «Population Composition in Prehispanic Mesoamerican Urban Settlements». En Urbanización y Proceso Social en América. Lima, 1972. pág. 262. 
No hay información demográfica precisa ni tampoco detalles concretos de distribución, sabemos únicamente con certeza lo side los señores. ${ }^{59}$

- Que fue una ínsula que creció mediante la construcción de terraplenes artificiales sobre el pantano.

- Que tuvo un elaborado sistema de canales, calles, calzadas y acueductos.

- Que la ciudad estaba dividida en su interior para efectos administrativos; dicha división data desde el origen cuando se instalan los famosos cuatro barrios al fundarse Tenochtitlan y que son los que menciona Durán. ${ }^{57}$

- Que los barrios grandes se dividían a su vez, en colonias o vecindarios más pequeños llamados tlaxilacalli, los cuales funcionaban como unidades de especialización económica similares a los gremios medievales en Europa, con una población aproximada de 1.875 a 2.500 personas. ${ }^{58}$

- Que los tlaxilacalli, por su parte, se formaban con casas o unidades habitacionales familiares, algunas de las cuales estaban asociadas a chinampas.

57 Fray Diego Durán: Historia de las Indias..., pág. 42. El aspecto de la división territorial en Tenochtitlan ha sido tratado por diversos autores. Monzón describe a la ciudad como un gran pueblo o altepetl dividido en cuatro acampan», término acuñado por el autor y que aplica a los cuatro barrios que surgen cuando la fundación; éstos se dividían en calpulli o barrios más pequeños, los cuales estaban formados por Taxila-calli, barrios menores que eran el conjunto de chinampas o parcelas familiares (Monzón, págs. 35-54). Por otro lado, tanto Caso como Sanders y Calnek manejan el término tlaxilacalli para indicar divisiones territoriales de carácter residencial dentro de la ciudad. Luis Reyes García, estudiando documentos del siglo XVI escritos en la ciudad de México sobre asuntos de la ciudad, analiza con precisión los términos altepetl, hueyaltepetl, tlaxilacalli y calpulli, concluyendo que la palabra indicada para referirse a una porción territorial dentro de la ciudad habitada por un número de familias sería el de tlaxilacalli, mientras que calpulli se entendería mejor refiriéndose a tierras relacionadas con templos o con dioses: concluye además que altepetl, contracción de yn atl yn tepetl, se reflere en términos generales a pueblo, huey altepetl, término que surge en la colonia cuando se introduce el sentido de ciudad a diferencia de pueblos (Luis Reyes García, «El término calpulli en Documentos del siglo XVI», pág. 34). Me refiero a tlaxilacalli en el sentido que lo usa Reyes García, es decir, a una división territorial urbana de carácter residencial.

58 Sanders, A tale..., pág. 53; dichos gremios pueden haber estado formados por artesanos diversos, labradores agricultores, en cuanto al común: o bien por guerreros importantes, comerciantes destacados. 
Que las zonas variaban según la posición social, ocupación o especialización, siendo la periferia lo del común y el centro lo de los señores. ${ }^{59}$

Por lo tanto se puede suponer que la ciudad estuvo dividida de la siguiente manera:

I Altepetl Tenochtitlan (el conjunto urbano en su totalidad).

II Barrios mayores (cuatro grandes divisiones o colonias que datan desde la fundación: Cuepopan, Moyotlan, Atzacualco, Zoquiapan).

III Tlaxilacalli (vecindarios menores).

Todo lo anterior parece indicar que el reparto citadino en Tenochtitlan no se había dado al azar, sino que era el resultado de un largo proceso histórico en donde habían intervenido factores económicos, sociales y políticos. El espacio urbano y la manera como éste se ordena está fuertemente influenciado por la organización del grupo en cuestión; la planta de la ciudad, a su vez, influye

59 Nota: Sahagún, Códice Florentino, Edición Facsimilar. Florencia, 1979. Libro Undécimo, «Casas Comunes»; Alfonso Caso dice al respecto que en los barrios había plebeyos y nobles por igual, mientras que Arturo Monzón, considera que los barrios eran eminentemente especializados y los había de señores y reyes como Yopico, Huitznahuac o Itepeyoc; no obstante ello considera el autor que las divisiones territoriales no se basaban en clases, sino en especialidades y ocupaciones solamente (Caso: La tenencia de la tierra entre los antiguos mexicanos. «Memoria de El Colegio Nacional». T. IV. núm. 2, México, 1959-1960, pág. 46; Monzón, El calpulli.... págs. 74-75). Se podría deducir que si bien no había una verdadera diferenciación en cuanto a las zonas de la ciudad, si existían ciertos predominios en ciertas áreas de la ciudad; además ciertos barrios de especialistas tienen que haber sido de mayor categoría puesto que las diferencias sociales se hallaban presentes en la ciudad; por ejemplo el barrio de los pochtecas, quienes se perflaban como una clase de alto rango a la llegada de los españoles. Blanca Paredes, basándose en investigación documental y arqueológica, demuestra la existencia de una diferenciación habitacional en la Cuenca de México para el Post-Clásico, definiendo viviendas comunes y residencias palaciegas localizadas en áreas diferentes (Paredes, pág. 251) y que eran el resultado de dos «formas de vida distintas (Ibidem, pág. 245). La mayor patre de las casas eran las comunes asociadas a chinampas y situadas en los barrios a los que Paredes llamaba «conjuntos habilacionales» (Ibidem, pág. 246), refiriéndose seguramente a tlaxilacallis. 
en las relaciones sociales y en la integración general del grupo. ${ }^{\text {(n) }}$ La tierra tenochca pudo haber sido, no solamente un sitio para habitar, sino un elemento ordenador de tipo económico, social y religioso dentro del orden cultural mexicano.

\section{LA VIVIENDA INDÍGENA}

Describe el Códice Florentino los diferentes tipos de casas refiriéndose no sólo a la capital tenochca sino también a distintas regiones del imperio mexica. Dichas diferencias en la construcción vistas por Sahagún se originaban desde luego y en primera instancial en el medio ambiente, pero también en el factor económico-social. La posesión y características de los inmuebles estaba rígidamente reglamentada y se derivaba directamente de la posición social (nobleza) y de la actuación en la guerra. Dice Durán que:

"Salió ordenado que ninguno fuese osado a edificar casa con altos, sino sólo los grandes señores y valientes capitanes so pena de la vida). ${ }^{61}$

Es decir, que las casas de dos pisos eran única y exclusivamente para los señores, considerándose la posesión de una de ellas como símbolo inequívoco de alto rango, ya que incluso iba la vida de por medio en la supuesta violación de dicha regla. Continúa fray Diego:

«... y que ninguno osase poner xacales puntiagudos ni chatos $\mathrm{ni}$ redondos en sus caças, sino sólo los grandes señores, so pena de

$60 \mathrm{Al}$ respecto se afirma que el urbanismo en Teotihuacan, donde los llamados conjuntos apartamentales (compounds) estaban situados en la periferia, provocaba una situación de dependencia del campo con respecto de la ciudad; es decir, la ciudad mantenía el control mediante una serie de mecanismos, uno de los cuales pudo haber sido la organización del espacio urbano y arquitectónico (Morelos, «el concepto de unidad habitacional...» en Manzanilla, Unidades habitacionales... pág. 204).

61 Fray Diego Durán: Historia de las Indias..., tomo I, págs. 214-215. 
la vida, porque aquéllos eran particular grandeza y merced de los señores, concedida de lo alto por los dioses sólo a ellos's. ${ }^{62}$

Los dioses directamente concedían ciertos privilegios «arquitectónicos» única y exclusivamente a los grandes señores; es así que la construcción juega un papel importante en la rígida pirámide social azteca, siendo un claro elemento de rango y jerarquía.

Por su parte Sahagún detalla veinte y seis tipos de vivienda diferentes, dentro de una amplia gama de categorías:

tecpan calli casas del señor.

tlatoca calli palacios de personas principales.

tecpil calli casas suntuosas de muchos edificios.

tlaco calli casa de azotea.

tlapan calli casa fuerte para guardar las cosas de los señores.

calpixca calli casas comunes.

sasan ie calli casa de mercaderes.

pochteca calli casa bien hecha.

nelli calli casa de villanos.

maceoal calli casa pequeña como pocilga.

tecoio calli casa humilde.

icno calli choza o cabaña.

colotic calli ermita.

xacalli

sasa ie xacalli

tlapica calli

tecoio xacalli

xacal tetzoiotl

casa pajiza.

otra manera de choza.

casa donde se esconden los guardas de los maizales.

otra manera de choza puntiaguda.

casa de tablas.

xacal mimilli otra manera de casa pobre.

quaub xacalli

otra manera de casa de tablas.

ipal xacalli

otra manera de casa de tablas.

calnepanolli

casa con sombrado.

tlallan calli

casa hecha a mano debajo de la tierra.

calbuivilaxtli

casas continuadas unas con otras.

caliacalli

chantli

casa redonda sin esquinas.

casa generalmente.

62 Ibidem, págs. 214-215. 
No señala Sahagún distinciones entre lo que serían las casas de la ciudad y las rurales; únicamente observa diferencias de categorías; en el nivel más alto se encontrarían quizás la tlatocacalli, que era «buena hermosa, precisa casa»; ${ }^{63}$ recordemos que el palacio de Moctezuma II ocupó una superficie de 2'4 hectáreas, ${ }^{64}$ o sea unos 24.000 metros cuadrados, siendo una estructura arquitectónica grande, compleja y lujosa, con salas, patios y corredores. Según Cortés, tenía: «sus casas de aposentamiento tales y tan maravillosas que me parecería casi imposible poder decir la bondad y grandeza de ellas... en España no hay semejante». ${ }^{65}$

El tecpilcalli o palacio de los nobles era: «preciosa, buena sutil, de buen parecer, agradable»; ${ }^{\text {ob }}$ el tlapancalli llamada por Sahagún «casa suntuosa de muchos edificios» y que sólo se permitía tener a la nobleza, era una casa de dos pisos.

La calpixcacalli, por su parte, se describe como «grande, alta, fuerte, recia, firme, modelo, de buen clima, templada»; ${ }^{67}$ en ella vivían los mayordomos, funcionarios encargados de algunas agencias en el palacio. La pochtecacalli o casa del mercader era: «de gran presunción, de fachada buena, fuerte, de apariencia vistosa y galana»; mientras que la nellicalli era «buena, recia y fuerte». ${ }^{\text {68 }}$

Parece ser que las casas de los señores eran grandes y que se construían con una especie de entresuelo posiblemente para evitar la humedad que en Tenochtitlan sería un problema importante; se dice también que en ellas había «huertas o vergeles», ${ }^{69}$ lo cual nos da una idea de lujo y deleite.

En un plano inferior estarían todo el resto de las casas descritas por Sahagún. Las sasan ie calli o casas comunes, las cuales

63 Sahagún, Códice Florentino, Libro Undécimo, «De las diferencias de Edificios», tomo I, pág. 303.

64 Calnek, «The Internal Structure..., pág. 352.

65 Cortés, Hernán: Segunda Carta de Relación, pág. 67.

66 Sahagún, Códice Florentino, Libro Undécimo, tomo I, pág. 303.

67 Ibidem.

68 Ibidem.

69 Motolinía, Memoriales..., pág. 309; Alonso de Zorita en García Icazbalceta, J.: Nueva Colección de Documentos para la Historia de México (siglos XVI y XVII). 5 tomos. México, 1886-1892, tomo IV. 
eran «no muy buenas, de ninguna manera estimadas, poca cosa, despreciadas, sin valor». ${ }^{70} \mathrm{O}$ bien los maceoalcalli o casas de villanos que eran «pobres, pequeñas despreciables, de vasallo, toscas, sin muro, sin protección, frías con viento, con agua», aunque con «buenos cimientos de piedra, con base firme». Dicho ejemplos y todos los demás citados en el Códice denotan la ausencia de calidad y de valor («de ninguna manera estimadas, poca cosa, despreciables, despreciadas»).

Según Torquemada, por lo general no se usaron puertas en las casas indígenas porque «no era necesario defender nada con ellas», solamente un «cañizo colgado de tejuelas» para ocultar o cubrir el interior de la casa. ${ }^{11}$ Este rasgo nos sigue dando idea de lo simple de la construcción, así como de la sencillez de la vida cotidiana («no era necesario defender nada con ellas»).

Se ha hablado de la existencia de «conjuntos habitacionales» (household compound) que serían quizás las calbuinilaxtli (casas continuadas unas con otras), comparándolas con los conjuntos apartamentales (apartment compound) que menciona Millon para Teotihuacan. ${ }^{72}$

Sin embargo, los conjuntos tenochcas parecen haber sido lo que hoy en día llamaríamos «casas solas», es decir, moradas independientes y con su propio acceso a la călle, pero construidas en yuxtaposición unas con otras, quizás incluso con muros medianeros. Los conjuntos teotihuacanos, en cambio, eran una serie de viviendas compartiendo espacios comunes, a manera de las viejas vecindades de la ciudad de México.

Sahagún habla también de los que «habitaban en barcas» o sobre «armazones de madera enclavados en el lago»; ${ }^{73}$ según el Códice Florentino durante el sitio: «...los que tenían casas en el agua, unos de ellos se fueron en canoas otros salieron apeando por

71 Torquemada, Monarquia Indiana, Lib. XII, cap. V, volumen IV, pág. 208.

72 Millon, The Teotihuacan map. págs. 1.079-1.080.

73 Sahagún, Historia General..., pág. 807. 
el agua, otros nadando, y llevaban sus haziendas y sus hijos a cuestas salían muchos de noche y otros de día». ${ }^{74}$

Tal vez algunos habitantes de Tenochtitlan vivían en canoas o en trajineras al estilo de los shampanes de Hong Kong o de Singapur; según las fuentes, después de la severa inundación sufrida por la ciudad en 1499, gran parte de los habitantes vivían en canoas, ${ }^{75}$ situación que bien pudo haberse prolongado hasta la llegada de los españoles. Recordemos que la voz náhuatl acalli tiene una etimología $($ atl $=$ agua, calli $=$ casa $)$ que podría en algunos casos, indicar ese tipo de habitación.

Se supone que las áreas residenciales eran pequeñas, con superficies que iban desde los 100 a los 500 metros cuadrados; cada área estaba ocupada por una o varias casitas en su interior que raras veces daban a la calle ya que por lo general, tenían la fachada hacia el patio. ${ }^{76}$ Parece ser que las construcciones podían estar en diferentes puntos del terreno y no necesariamente alineadas a la calle. Esta forma arquitectónica tan característica de la región fue quizás lo que desconcertó al español y le hizo pensar en un desorden urbano. El patio fue siempre un lugar muy importante en la vida cotidiana y posiblemente en el trabajo artesanal también; las construcciones estaban por lo general formadas de una sola pieza que servía para todo: dormir, comer, descansar, etc., es decir, que no había espacios especializados; la cocina, por ejemplo consistía en un brasero primitivo al aire libre o en el piso dentro de la vivienda y era básicamente tres piedras sueltas en donde se formaba el fuego y sobre las que se colocaba el comal (comalli) para hacer las tortillas

74

«Auh in ACALEQUE in ixquich acale caioaltica inquiz, yoalelcemilhuitl in quzique iuhquiu moquequeztiui injeui»

Acaleque = casas en el agua, Códice Florentino, Libro duodécimo ade la conquista mexicana», capítulo 40 , pág. 488 vta. (Subrayados míos).

75 Sahagún, Historia..., pág. 499; Clavijero, Historia Antigua de México. 6.^ Ed. México, 1979, pág. 123. Durán, Historia de las Indias, pág. 394.

76 Dichas características son de gran antigüedad en el Valle de México, según la evidencia proporcionada por Teotihuacan, se encontraron en el área más de 2.000 recintos residenciales todos con un patio interior. René Millon. The Teotihuacan map. En Tezcoco, según relato de Pomar, la mayor parte de las casas tenían patio y á la redonda de él los aposentos». Pomar, Juan Bautista: «Relación de Tezcoco» en Nueva Colección de Documentos para la Historia de México, editados por García Icazbalceta, tomo II, págs. 62-63. 
o bien las ollas o las cazuelas según lo que se fuera a cocinar; por allí estaría el metate (metlatl) o piedra para moler o el molcajete (molcaxitl), vasija pequeña de piedra para moler pequeñas cantidades y quizás unos cuantos cacharros de barro. Algunas casas tenían el llamado teotzintle, especie de adoratorio doméstico; otras tendrían un temazcalli o baño de vapor. En raras ocasiones se encontraban dos piezas en una sola edificación; podemos suponer que estas últimas pertenecían a la nobleza, mientras que las de una pieza serían las del común. Tenían una superficie aproximada de 10 metros cuadrados como mínimo y 40 como máximo. ${ }^{m}$

Parece ser que hubo variedad en las construcciones, siendo el techo un elemento indicativo de la calidad de las mismas. Las más humildes estaban construidas con techos de paja (xacalli), mientras que los de una posición más acomodada vivían en casas de argamasa barata con empalizada (cacan ie calli), habiendo también viviendas de adobe con techos de vigas (tlapan calli, tlacocolli, tlatocacalli). No es lo mismo, desde luego, techar a base de paja requiriendo mínimo tiempo, esfuerzo y material, que realizar un techo de vigas con material caro, escaso y con mayor necesidad de conocimientos constructivos, ${ }^{78}$ reflejándose en ello una diferencia económica importante.

Los techos planos fueron típicos del centro de Tenochtitlan, tan es así que llaman la atención a Cervantes de Salazar quien comenta al respecto la diferencia con las construcciones españolas hechas con tejados, diferencia que atribuye a la inseguridad de la tierra por los temblores y también a la mala calidad del subsuelo pantanoso. ${ }^{79}$ Según Kubler, estos planos permitían el uso de las

77 Calnek, «Conjunto urbano y modelo residencial en Tenochtitlan».

78 Blanca Paredes menciona un techo similar de vigas hecho a base de troncos delgados perfectamente pegados entre sí, de manera que no podría filtrarse el agua. Paredes, \&La unidad habitacional en la Cuenca de Méxicos en: Linda Manzanilla, Unidades habitacionales..., págs. 221, 256. Juan Bautista Pomar describe esta técnica de techar de la manera siguiente: *Tienen las cubiertas con vigas, y en lugar de tablas con muchas astillas muy menudas, tan bien puestas que no se cuela por entre ellas ninguna tierra de la que ponen encima para terrados. Pomar. «Relación de Tezcoco» en Nueva Colección de Documentos..., de García Icazbalceta, págs. 62-63.

79 Cervantes de Salazar. Francisco: México en 1554 y Túmulo Imperial. México, 1975. 
azoteas para el cultivo de plantas y de flores, sin especificar con detalle de qué manera lo hacían. Más tarde, durante la colonia, la floricultura continúa siendo muy popular usándose para entonces las macetas. ${ }^{80}$

Podemos suponer que si en verdad los techos planos predominaban en el centro de la ciudad, la construcción debe haber sido de relativa buena calidad cuando menos en esa área, donde se encontraban las mejores viviendas, puesto que las llamadas taplan calli o casas de azotea eran construcciones sólidas:

"casal de azotea quiere decir que no es choza $\mid$ sinol casa de madera entablada, sobre vigas".

Por otro lado, en las zonas lejanas al centro lo usual serían los jacales (xacal mimilli), de los cuales Sahagún consigna unal docena, la mayoría pobres, sencillos y con techos de paja. En el altiplano se acostumbraba también techar las construcciones con una capa gruesa de barro: tales techos se siguieron usando durante toda la época colonial, incluso en la capital; para impermeabilizar las azoteas se usaban resinas o salitres. ${ }^{81}$

Suponemos, a partir de todo lo anterior, que los materiales usados pueden haber sido los siguientes:

\section{Vegetales}

La madera. Una de las riquezas de la Cuenca de México en el siglo XVI estaba constituida por las enormes zonas madereras, habiendo en ellas ciprés, cedro, pino, encino, roble y ayacábuatl; ${ }^{82}$ Sahagún nos habla de este último como de una madera muy estima-

80 Kubler, George: Arquitectura mexicana del siglo XVI. México, 1983, pág. 178. El cultivo de flores fue siempre de importancia desde la época prehispánica hasta bien entrada la vida colonial, véase Theatro Americano, de José Antonio de Villaseñor y Sánchez. México, 1986, pág. 60.

81 Kubler, Arquitectura..., pág. 171.

82 Sahagún. Códice Florentino, Parrapho Segundo, Libro Undécimo, «De los Arboles Mayores», págs. 263, 265. 
$\mathrm{da}$, menciona también el ciprés silvestre como una madera preciosa para edificios, habla del oiametl como un pino para sacar resinas $y$ de los fresnos llamados ylin. ${ }^{83}$

Las zonas aledañas proveían a la isla de material de construcción como la piedra, cal, tezontle, etc. Además Tenochtitlan recibía periódicamente por concepto de tributos las siguientes cantidades consignadas en el Códice Mendocino: 1.200 vigas grandes de madera; 1.200 tablones o tablas gruesas; 1.200 tablones angostos llamados morillos, llegaban a la ciudad cada ochenta días provenientes de trece pueblos de diferentes regiones: Quaquauhcan, Tecpan, Chapulmaloyan, Tlalatlauco, Acaxochic, Ameyalco, Acotepec, Uitzquilocan, Coatepec, Quauhpanoayan, Tlatlaxco, Chichicpuautla y Uitzitzilapan. ${ }^{84}$

Estos datos nos indican la enorme cantidad de madera usada en la ciudad. La tala del bosque en la parte sur del Valle de México fue de gran envergadura; en el Mapa de Upsala aparecen figuras de leñadores bajando de dicha zona, la cual vivía precisamente de la explotación del bosque, sobre todo después de la fundación de Tenochtitlan, cuando la construcción se incrementa con intensidad. ${ }^{85}$ La madera se usó en los muros de las casas, en los techos y como cimentación a base de pilotes introducidos en la tierra en gran cantidad, costumbre de origen prehispánico que después fue practicada con éxito por los españoles en Tenochtitlan durante el siglo XVI. ${ }^{86}$

El carrizo.- - Se encuentra por lo general en las márgenes de los ríos o en la ciénega y se usaba en las armaduras de los techos o en los muros de las casas. ${ }^{87}$ carrizo.

El otate y el junquillo.-Usados de la misma manera que el

83 Ibidem.

84 Codice Mendocino, Lámina 32.

85 Cabrero G., M.a Teresa: Un área rural en la periferia de Tenochtitlan. estudio arqueológico en «Anales de Antropología», México, 1979, págs. 21-23.

86 Kubler, Arquitectura..., pág. 182.

87 Datos de materiales tomados de Moya Rubio, Víctor: La Vivienda Indiyena èn México y en el Mundo. México, 1984, págs. 34-39. 
La penca del maguey.-Recortada y prensada sirve para cubrir paredes y techos y también para canales, típica del altiplano. ${ }^{88}$

Las espinas de maguey.-Usadas como clavos o tachuelas. ${ }^{81}$

El quiote.-De quiotl, tallo del maguey utilizado como viga.

La ramazón o ramas y los esquilmos de las cosechas.-Usados ambos para ubrir paredes y techos una vez secos.

La tableta o el tejamanil.-Tablones de madera delgada usada en las cubiertas de los techos y la tableta en los muros.

Troncones o morillos.-Piezas de madera larga usadas como columnas o bien como vigas para los techos. De lo anterior nos da Sahagún el siguiente recuento:

A las viguetas les llaman quauacatl.

A los rollos quautentli o quaubmimilli.

A las vigas del entresuelo ueuetzqui o uepanton.

A las plancbas elquaubiotl.

A las tablas oapalli.

A los tablones tlapechoalli.

A los postes que sustentan la pieza ilbuicatl. ${ }^{*}$

\section{Minerales}

El tezontle.-(Teçontli = piedra tosca, llena de agujeritos y liviana). ${ }^{91}$ Fue usada desde el gobierno de Ahuizotl, cuando las grandes obras en Tenochtitlan para la construcción de los templos; ${ }^{92}$ muy útil por su ligereza y dureza combinada, sobre todo en

88 Motolinía, Memoriales, pág. 264; Cervantes de Salazar, México en 1554, pág. 146.

89 Ibidem.

90 Sahagún, Historia General.... Libro XI, Cap. VI, párrafo 5. El uso de la madera en la ciudad española no sólo continúa, como en la época prehispánica, sino que se incrementa fuertemente, de manera que, a pocos años de fundada la ciudad cortesiana «...las faldas de los montes están muy talados», por lo cual el Ayuntamiento propone que se obedezcan las ordenanzas y pragmáticas dictadas al respecto (Actas de Cabildo, 29 oct-1533).

91 Fray Alonso de Molina, Vocabulario..., pág. 23. pág. 168.

92 Torquemada. Monarquía Indiana, vol. 1, pág. 266; Kubler, Arquitectura..., 
un subsuelo tan deficiente como el de la isla sobre el que los materiales de mucho peso eran poco prácticos. Derivado del tezontle se usaba también la arena de tezontle conocida como tezontlalli «polvo de toba volcánica, con que se hace argamasa». ${ }^{93}$

".... $\Lambda_{y}$ una tierra vien conozida que se llama teçontlalli quees y se usa para mezclar con la cal y hazela muy fuerte véndese mu. cho aquí en México para los edificios”. ${ }^{94}$

La cantera.-Labrada en bloques y que posiblemente fue muy usada en la ciudad prehispánica puesto que los canteros tenochcas, así como los de Texcoco, eran bien conocidos por su experiencia en labrarla. ${ }^{95}$

El recinto.-Tallado en las escalinatas y también de gran uso, como se puede ver en los restos arqueológicos.

La piedra.-De distintas calidades y medidas, usada en la mampostería de los muros, en los cimientos y también en los pisos.

\section{Manufacturados}

El adobe.-Tradicionalmente usado en las construcciones prehispánicas y aún después de la colonia e incluso hasta finales del siglo XIX; el uso del ladrillo y de la teja no se generalizó sino hasta 1580 en México, ${ }^{96}$ Sahagún habla del adobe:

(1...una tierra que se llama atçatl que es blanca y blanquecina, que tiene greda mezclada: por tiempo se buelve enfreda, hazen della adoues; no es buena para otra cosa). ${ }^{97}$

93 Sahagún, «Vocabulario» en Historia General..., pág. 949.

94 Códice Florentino, Libro XI, pág. 382, «De las tierras».

95 Motolinía. Memoriales, pág. 209.

96 Kubler, Arquitectura..., pág. 171.

97 Códice Florentino, «De las tierras». 
El adobe, material típico del altiplano, consistía en bloques hechos a mano con una mezcla de barro y agua, agregándoles a veces paja para darle mayor consistencia; según Pomar, la mayor parte de las casas de Texcoco eran de adobe, material de gran durabilidad, puesto que había edificios de más de doscientos años hechos de adobe $y$ en buenas condiciones. ${ }^{98}$

\section{Aglutinantes}

El barro.-Mezclado con agua y algunas veces con paja para obtener mayor consistencia, usado también en el aplanado de las paredes y en algunos techos.

La cal._En su estado natural se encuentra mezclada con ot rats sustancias.

El lodo.-Mezclado con agua para unir y asentar piedras en el terreno, revocar las paredes hechas con varas, dando buen resultado puesto que no se desprende ni agrieta con los cambios de temperaturas.

Resinas.-Como el oiametl, usadas en la impermeabilización de las azoteas.

Vemos con todo lo anterior que la construcción doméstica de la mayor parte de los tenochcas es realmente sencilla, poco desarrollada y bastante perecedera; sólo las grandes pirámides, palacios y algunos otros edificios tenían más firmeza, resistencia y durabilidad. ${ }^{99}$ De la lista consignada por Sahagún, que son 26 en total, solamente siete, que serían aproximadamente la cuarta parte, se

98 Pomar, «Relación de Tezcoco» en Nueva Colección..., de García Icazbalceta., tomo II, págs. 62-63.

99 Acerca de la construcción de las pirámides nos comenta Ignacio Marquina lo encontrado por él en el templo Mayor de Tenochtitlan: «...tanto la alfarda como los escalones estaban cubiertos por un concreto de cal, tezontle y otros materiales que tuvimos que romper con marro y cuña de acero pues su dureza era tal como la del concreto de cemento usado actualmente; a veces se presentaba la apariencia de granito natural». Marquina, Ignacio: El templo mayor de México, México, 1960, pág. 115. 
pueden considerar como de calidad; ${ }^{100}$ el resto de las casas denotan escasez y pobreza.

Las diferencias en los estilos de la construcción mexicana nos dan una idea de los diversos modos de vida derivados de las desigualdad social, presente en la Tenochtitlan del siglo XVI, en los albores de la conquista.

Aunque es sumamente aventurado hacer afirmaciones concretas sobre las distintas clases dentro de la ciudad, sí se puede suponer que las formaciones sociales deben haber sido de mayor complejidad que la simple división pipiltin versus-macebualtin que predominaba en las zonas rurales. Dentro de las masas urbanas tenochcas debe haber habido una gran diversidad de intereses económicos $y^{\prime}$ de situaciones diferentes, ${ }^{101}$ las cuales se reflejan gráficamente a través de la construcción doméstica y en el formato general de la ciudad.

\section{LA PROPIEDAD EN LA CIUDAD}

Aunque es un tema muy discutido por diversos investigadorcs, se puede decir que las formas de posesión de la tierra debidamente identificadas en el México prehispánico son únicamente la comunal y la de administración estatal. ${ }^{102}$ Parece ser que no hubo propiedad privada como la entenderíamos en la actualidad; sin embargo, sc puede afirmar que una forma de tenencia de la ticrra tendía ya

100 Serían las siguientes: tlatocacalli, tecpilcalli, tacocalli, calpixcacalli, pochteca calli, nelli calli, tlapancalli.

101 Calnek, Edward A.: «The Sahagún texts as a source od Sociological Informacion», en Edmondson. Munro (Ed.): Sixteenth Century Mexico; The work of Sahagún. Albuquerque, 1974, pág. 193.

102 El tema de la tenencia de la tierra ha sido ampliamente tratado por los diferentes estudios del México antiguo como Diego Durán en su Historia de las Indias de Nueva España. Capítulo XI: Alonso de Zorita en su obra Los Señores de Nueva España en las págs. 30 a 35: Francisco Javier Clavijero en la Historia Antigua de México, libro VII, núm. 14. En la época contemporánea Alfonso Caso en La tenencia de la tierra entre los antiguos mexicanos y Víctor Castillo F. en la Estructura económica de la sociedad mexica lo analizan con amplitud y precibión; Charles Gibson, a su vez, abunda en el tema en el capítulo décimo de su obra Los aztecas bajo el dominio español. 
hacia la propiedad privada tanto de hecho como de derecho en el momento de la llegada de los españoles, ya que desde fines del período azteca se detectan asignaciones de tierras diversas en una manera que podría considerarse como propiedad particular. ${ }^{103}$

Después de la guerra de Azcapotzalco en 1428, Itzcoatl implanta dos nuevas disposiciones que van a reforzar las diferencias económico-sociales entre pilli y macebualtin. Dentro de la primera crea una nobleza palaciega dando a sus parientes los más altos cargos religiosos y políticos, y dejando a los plebeyos totalmente excluidos de la administración del Estado.

La segunda disposición que es la que nos interesa, organiza una especie de propiedad privada de la tierra única y exclusivamente para los pipiltin, creando así una diferencia económica íntimamente ligada a la diferencia de sangre. ${ }^{104}$ Solamente los pilli descendientes de Acamapichtli, algunos individuos muy destacados en la guerra ${ }^{105}$ y ciertos mercaderes útiles para el estado mexica ${ }^{106}$ podían aspirar a tener posesión territorial privada, distinción derivada precisamente de su posición en la pirámide social. Los miembros de la nobleza indígena podían transmitir a sus hijos los derechos sobre las tierras e inclusive las podían enajenar, siempre y cuando no lo hicieran a individuos del común, restricción ésta que limitaba mucho los derechos sobre la propiedad y que reforzaba con energía las diferencias económico-sociales de la sociedad mexica.

Vemos así que la verdadera propiedad de la tierra recaía solamente en dos entidades: el calpulli, especie de persona moral cuyos

103 Véase el Códice Ramírez, págs. 57-60 en las que se menciona el reparto hecho por Itzóatl de las tierras de Coyoacán entre sus principales; Baltasar Doranles de Carranza hace mención del reparto de las tierras de Xochimilco en la Sumaria Relación de las Cosas de Nueva España, México, 190\%, pág. 3, véase también la «Carta a S. M. de Sebastián Ramirez de...» en la Colección de Documentos Inéditos Relativos al Descubrimiento, Conquista y Colonización de las Posesiones españolas en América y Oceanía. Madrid, 1864, vol. XIII, pág. 257 en donde se afirma que *Moctezuma tenía caballerías de tierra, las cuales daba a los que se decian valientes hombres de México, que eran las personas que habían hecho cosas señaladas en las guerras....

104 Durán, Historia de las Indias..., pág. 60; Códice Ramírez, pág. 60. Joseph de Acosta, Historia Natural y Moral de las Indias, pág. 343; A3lfonso Caso, La tenencia de la tierra.... pág. 36.

105 Códice Ramirez, págs. 50-60.

106 Gibson, Los aztecas..., pág. 270. 
miembros trabajaban y usufructuaban las tierras, y el tlatoani quien como máxima autoridad las adjudicaba a los templos (teopantlalli), al palacio (tecpantlalli), al ejército (milchimalli), a los nobles (pillali) o bien a él mismo.

Por lo tanto, las casas en la ciudad, así como las parcelas en donde se encontraban construidas, pertenecían al calpulli y eran asignadas por los tlatoque, tequitlatos, calpullec o algún otro funcionario del calpulli. ${ }^{107}$

Un jefe de familia macebual podía gozar de la casa y del tlalmilli o pequeña milpa adyacente a la casa (en los casos en que la hubiera dentro de la ciudad) siempre y cuando cumpliera puntualmente con sus obligaciones fiscales, teniendo también el privilegio de dejarla a sus descendientes, si es que éstos a su vez eran cumplidos; pero los derechos de posesión se terminaban si el individuo se ausentaba de la propiedad por dos años. ${ }^{108}$

En el caso de los pipiltin la posesión sería más sólida; desde luego no tenían ninguna obligación fiscal al respecto, pudiendo además heredar la propiedad libremente y en algunos casos también enajenarla. La realidad de las cosas es que el reparto era sumamente desigual ${ }^{109}$ y la tierra se concentraba en unas cuantas manos, lo cual afirmaba el sistema de preeminencia social, riqueza e influencia política del grupo de escogidos formado por el rey, los nobles y los guerreros que eran los grandes latifundistas de la época. Esta propiedad, no transmisible fuera del grupo aristócrata, era naturalmente un comercio inaccesible para las masas de población. ${ }^{110}$

107 Caso, La tenencia..., pág. 45; Castillo F., Estructura económica..., pág. 78.

108 Gibson, Los azteca.... pág. 274; Caso, La tenencia..., pág. 45.

109 Motolinía. Memoriales, pág. 352.

110 Según el padre Acosta, la principal parte de las tierras repartidas: ccupo al rey, luego a Tlacaellel; después a los demás nobles, según se habían señalado en la guerra...». Una vez hecho este reparto y ya en un cuarto lugar, se: «señalaron también tierras de común para los barrios de México... y éste fue el orden que siempre guardaron de alli adelante en el repartir las tierras» (Acosta, Historia.... pág. 343). Por su parte, Durán señala que al rey se le dieron konce suertes de tierra», a los principales ados y tres suertes «y a otros una» (Durán. Historia de las Indias..., pág. 101). Con lo anterior vemos que la riqueza del rey era de 3 a 10 veces mayor que la de los nobles, mientras que a los macehuales ni siquiera se les menciona por no recibir nada. 
Aunque es muy aventurado el poder afirmar el hecho de yice la tierra se veía ya como un medio de inversión, sí se podría suponer, aunque con cierta cautela, el que el grupo aristócrata, por derecho propio, y algunos comerciantes, por adquisición, se beneficiaban con la concentración de propiedad rural, cuyos productos guardaban en algunos casos para especular:

"...los principales y mercaderes, ésos, troxes y hacienclas ticnen y lienes con que sustentar). 11

Naturalmente, el caso de la propiedad urbana es diferente puesto que no era un medio de producción primaria como el campo; sin embargo, la existencia indudable de talleres artesanales le daba cierto valor mercantil indirecto. ${ }^{112}$

El valor de la tierra urbana se puede suponer con toda claridad en el caso de Tenochtitlan, ciudad con una infraestructura definida a base de calles, acequias, templos, mercados, almacenes y sistemas hidráulicos; abastecida por un sinnúmero de bienes tanto de primera necesidad como de carácter suntuario; tierra asimismo valiosa por su localización en un área de altísima productividacl agrícola, ${ }^{113}$ con un eficiente sistema de transporte lacustre, elemento de especial importancia en una región en donde se carecía de ani. males de tiro y con una alta densidad de población.

ก1 Durán. Historia de las Indias.... pág. 246.

112 El caso de acumulación y de inversión por parte de los comerciantes se da con toda claridad en el período colonial temprano, cuando las transacciones entre dicho grupo y los miembros de la nobleza se llevaron a cabo con toda formalidad. Existe el ejemplo de la india Angelina Martina, vecina de Santiago Tlatelolco, en el barrio de San Martín Telpochcaltitlan «... de la parte de los mercaderes...», dueña de 19 propiedades, bienes raíces, compradas a lo largo de sus 80 años, Angelina declara tener 81 años en 1581 . de manera que habría nacido en 1500 , siendo hacia finales del siglo una mujer rica. A.G.N., Ramo de Tierras, col. 49, exp. 5.

113 Sanders calcula que alrededor de 10.000 hectáreas de campos chinamperos estaban en plena produccion solamente en la parte sur de la Cuenca de México; supone el autor que por lo menos medio millón de personas se podían alimentar con los productos de la zona (Sanders, «Settlement Patterns» págs. 176-177). Por su parte Pedro Armillas calcula que habría más de 9.000 hectáreas de chinampas en el área a principios del siglo XVI en la Cuenca mexicana. 
La fuerte inversión económica que recibió la isla de Tenochtitlan durante el período azteca se percibe a través de las diversas crónicas hechas en el siglo XVI. Por poner sólo un ejemplo, la obra realizada a mediados del siglo XV bajo el gobierno de Moctezuma I para evitar las fuertes inundaciones de que era víctima la ciudad por estar situada en la parte más baja de la Cuenca, fue sencillamente admirable. La ingeniería indígena ideada por Nezahualcóyotl resultó un éxito para Tenochtitlan, aunque debe haber sido costosísimo. Poco después de 1446 participan en la obra del albarradón bajo las órdenes de Nezahualcóyotl: Totolihuatzin, señor de Tlacopan; Xilomatzin, señor de Culhuacán; Cuitlahuatzin, señor de Iztapalapa y Chimalpopoca, señor de Tenayuca. ${ }^{114}$ Dice Torquemada que «fue hecho muy heroico y de corazones valerosos intentarla porque iba metida casi tres cuartos de legua (la albarrada) el agua dentro y en parte muy honda y tenía de ancho más de cuatro brazas y de largo más de tres leguas». ${ }^{115} \mathrm{El}$ albarradón era un dique gigantesco que partía de Atzcacoalco en el norte hacia Iztapalapa en el sur al pie del cerro de la Estrella, hecho de piedra y barro con un muro de mampostería que a su vez estaba cubierto a ambos lados por una fuerte estacada que rompía las olas y tenía una extensión de 16 kilómetros. Según Torquemada, lo más admirable de la obra es «la brevedad con que se hizo que parece que ni fue oída ni vista»; en ella usaron piedras «muy grandes y pesadas» que por supuesto no habría en Tenochtitlan por lo que las tuvieron que traer «de más de tres y cuatro leguas de allí). El costo de acarreo del material de construcción a base de energía humana, transportando piedras «muy grandes y pesadas» e infinidad de estacas «muy gruesas» debe haber sido sensiblemente alto. Además «la brevedad con que se hizo» aumentaría mucho el costo ya que se infiere que la cantidad de obreros que intervino en la obra para hacerla especialmente rápida

114 Clavijero, Historia Antigua de México, pág. 108; González Obregón, Luis: Reseña histórica de las inundaciones y desagüe del Valle de México, Manuscrito, s./f., pág. 16. Riva Palacio, Vicente: México a través de los Siglos. 5 tomos. México, s./f., tomo II, págs. 98-99.

115 Ramírez, José Fernando: Memoria acerca de las obras e inundaciones en la Ciudad de México. México, 1976, pág. 34. 
sería mucho mayor que a un paso normal, aparte de los buzos y operarios especializados que necesariamente trabajaron en la realización del albarradón.

Además la albarrada controlaba perfectamente las aguas, probablemente por medio de compuertas que se abrían en la estación de secas para verter las aguas dulces excedentes en el lago de Texcoco. Mientras que en tiempos de lluvias las compuertas se cerraban para evitar el que las aguas salobres invadieran la región occidental del lago; además los indios habían construido también diques y compuertas para impedir la invasión de las aguas del sur en Mexicalzingo y en Tláhuac, dividiendo así el lago de esta región en dos, que eran los de Chalco y Xochimilco, todo ello en beneficio de Tenochtitlan.

Sin embargo, los pueblos de Chalco, Mixquic, Cuitlahuac, Xochimilco y Culhuacán sufrieron inundaciones provocadas precisamente por el sistema hidráulico construido en beneficio de Tenochtitlan, ya que los lagos del sur de la Cuenca aumentaban el volumen contenido en sus vasos al ver represadas las agulas, las cuales se alojaban entonces a orillas de dichos pueblos, con el consiguiente perjuicio. A pesar de ello, Tenochtitlan con gran autoridad y despotismo, controlaba las aguas de la misma manera que lo había hecho con los señoríos, gozando de innumerables ventajas resultado de las obras hidráulicas efectuadas en los lagos. ${ }^{110}$

Los indígenas de México, tanto en el período azteca como también durante la colonia, estaban perfectamente conscientes del valor de la tierra a la cual cuidaban y guardaban con especial celo; abundan los documentos que nos lo demuestran.

"...la casa nos la heredaron nuestros abuelos difuntos llamados Chimaltzin y Tiacapantzin... la casa es nuestra pertenencia, es nuestro bien, es nuestra tierra y nuestra casa ". ${ }^{117}$

116 González Obregón, Reseña histórica de las inundaciones.

117 Documentos de la Ciudad de México de Luis Reyes et al. (En Prensa). 
Scgún relata Torquemada, a los hijos que dilapidaban su herencia o la desperdiciaban o gastaban mal los ahorcaban; ${ }^{118}$ el hecho de aplicar la pena máxima al hijo que malgastaba la herencia nos indica que los indios nobles daban a ésta el mismo valor que a la vida, es decir, que tenían en altísima estima a la tierra, que era de los pocos bienes que se podían heredar.

(esto es lo que nuestros abuelos y nuestros padres dejaron...". "Hijos mios, vosotros debéis guardarlo como el pueblo de Dios. Nuestros abuelos y nuestro padres lo ganaron...). ${ }^{119}$

El énfasis que se da al valor de la herencia va íntimamente ligado al sentido de propiedad, concepto que para la época se percibe como de fundamental importancia. ${ }^{120} \mathrm{Y}$ no solamente la tierra se cuidaba y se celaba con especial vigor, el agua también, según se ve en la Ordenanza dictada por Cuauhtémoc para el «reparto de la laguna grande de Tezcuco». Dicha cédula contiene y da cuenta del lindero perfectamente trazado en medio de la laguna y en donde estaba el Çua perteneciente a Tlatelolco y a Tenochtitlan. Este documento insiste en la necesidad de cuidar las propiedades ganadas por los antiguos mexicanos con «muchísimos trabajos» y reitera con energía el valor de la propiedad, ${ }^{21}$ si bien en este caso se rebasa el valor que un individuo o familia le da a la tierra ya que es tierra y laguna del Señorío todo.

Al llegar los primeros grupos a la isla original se hizo un primer reparto de las tierras disponibles en cuatro calpulli princi-

118 Biblioteca Nacional de México, ms. núm. 1.312, fols. 22r. ss.; Gibson, Los aztecas..., pág. 278.

120 Muchos otros ejemplos se registran en el Archivo General de la Nación en el Ramo de Mercedes, volúmenes 1 y 2 ó en el Ramo de Tierras correspondientes al primer siglo de la conquista, en donde los asuntos tratados se refleren exclusivamente a pleitos y diferencias sobre propiedades, lo cual demuestra el inmenso interés que en ellas había.

121 Cédula dada por el Emperador Quauhtemotzin para el reparto de la. Laguna grande de Tezcuco en 1523, editor Vargas Rea, México, 1943. 
pales de una manera equitativa, dependiendo de la cantidad de gente que los iba a ocupar; sin embargo, en el momento de la llegada de los españoles es muy posible que dicho reparto equitativo de un principio se hubiera ya desequilibrado puesto que, según Zorita, no todos los calpulli tenían la misma cantidad de gente, ${ }^{122}$ por lo tanto algunos de ellos disponían seguramente de más tierras en relación con la gente que los habitaba. ${ }^{123}$ Ello debe haber provocado conflictos, cosa que se puede inferir del severo reglamento que ordenaba su posesión. Las parcelas eran indivisibles, ${ }^{124}$ existiendo pena de muerte para el que de alguna manera cambiara o alterara los mojones que delimitaban cada terreno. ${ }^{125} \mathrm{La}$ invasión de tierras de un calpulli por gente de otro era motivo de enormes pleitos. ${ }^{126}$ Mencionan los cronistas la existencia de mapas indicando perfectamente los distintos tipos de propiedad por medio de colores; así, las tierras del calpulli se señalaban con amarillo, las del rey estaban pintadas de rojo o púrpura y las de los nobles de rosa. ${ }^{127}$

Por otro lado, sólo los miembros del calpulli tenían derecho a tener tierras dentro del mismo y quienes lo abandonaban perdían automáticamente sus prerrogativas. Con ello podemos imaginar que el hecho de dejar el calpulli debe haber sido excepcional puesto que de él dependía el modus vivendi del individuo; tal vez la rígida reglamentación existente con respecto a la posesión de la tierra se había dado como resultado de una posible escasez de terreno cultivable, fenómeno que pudo quizás también presentarse en el área urbana de Tenochtitlan. ${ }^{128}$

122 Zorita, Breve y Sumaria relación..., pág. 88; Torquemada, Monarquia Indiana, tomo II; Monzón, El calpulli..., pág. 60.

123 Gracias a los beneficios de una agricultura intensiva la población había aumentado sensiblemente en poco tiempo, la tierra por lo tanto empezaba a escasear de tal modo que, a la llegada de los españoles, la relación hombre-tierra estaba en el umbral de lo critico (Wolf, Eric: Pueblos y culturas de Mesoamérica. Mc Neill, William: Plagues and People, cap. V).

124 López de Gómara, Francisco: Historia General de las Indias, en tomo II de la Biblioteca de la Iberia, pág. 277, México, 1870.

125 Ixtlilxóchitl en Monzón, El calpulli..., pág. 61; Torquemada, Monarquia Indiana, Lib. XII, cap. VII, pág. 115.

126 Caso, La tenencia.... pág. 46; Torquemada, Monarquia Indiana, tomo II, Zorita, Breve y Sumaria relación..., pág. 88. Monzón, El calpulli.., pág. 60 .

127 Monzón, El calpulli..., pág. 47.

128 Ibídem, pág. 61. 
Por lo tanto en el momento del contacto la tierra, tanto rural como urbana en la Cuenca de México, tiene un alto valor; el espacio parece haber estaclo totalmente repartido, ocupado y organizado.

\section{Concilusiones}

Hacia el primer cuarto del siglo XVI, el pequeño archipiélago que emergía al oeste de los lagos de la cuenca mexicana, se había convertido a través de doscientos años, en una aglomeración metropolitana con características urbanas definidas. Este lugar albergaba a una población que para 1519 pudo haber llegado a los 200.000 habitantes.

Un ordenamiento socioeconómico parece haber determinado el reparto del terreno dentro de la ciudad, de tal manera que las actividades de producción, de intercambio y de culto estaban íntimamente ligadas al espacio urbano.

A pesar de que la construcción doméstica era bastante elemental y sencilla, es probable que el elemento arquitectónico dentro de la ciudad haya desempeñado también un papel discriminador en la estructura social mexica, dictando ciertas normas que acentuaban y reforzaban rangos y jerarquías.

Por otro lado, todo indica que la tenencia de la tierra era de carácter comunal, siendo para el individuo únicamente el usufructo; sin embargo, existen razones para suponer que poco antes de la conquista, los miembros de la nobleza indígena (pilli) disfrutaban un tipo de posesión territorial más firme, más sólido y que se acercaba ya al concepto de propiedad privada. Formaba entonces esta aristocracia un grupo privilegiado que detentaba incluso ya una acumulación de la tierra.

Dicha situación pudo haber provocado una mayor polarización dentro de las distintas clases sociales indígenas que vivieron en México-Tenochtitlan hacia el primer cuarto del siglo XVI.

$$
\text { Ana Rita Valero de García Lascurain }
$$

